\title{
Detection of Fracture in Steel Members of Building Structures by Microstrain Measurement
}

\author{
Jun lyama ${ }^{1} \mathbb{D}$ \\ Received: 2 September 2019 / Accepted: 8 September 2020 / Published online: 16 September 2020 \\ (c) The Author(s) 2020
}

\begin{abstract}
This paper discusses a possibility of detecting structural damage caused by an earthquake, by measuring the time history of the strain of beams and columns before and/or after the earthquake. An index called "local stiffness" is defined as the ratio of section force amplitude to representative displacement amplitude, and this ratio can be physically interpreted as stiffness. By calculating section force amplitude at a section or node from the measured strain amplitude under a microtremor or small aftershocks and comparing it with the results of a static pushover analysis, it becomes possible to detect any structural damage, such as fractures. This methodology was applied and the microstrain data of a steel moment frame were measured in a large-scale shaking table test; beam-end fractures were observed after some excitation tests. After the beam-end fracture formed, the measured local stiffness dropped significantly below the analysis value, indicating the possibility of employing this value to detect fractures using the analysis value as a threshold value.
\end{abstract}

Keywords Structural health monitoring $\cdot$ Strain gage $\cdot$ Shaking table test $\cdot$ Microtremor

\section{Introduction}

Structural health monitoring (SHM) is a research field that has received considerable attention. SHM has been applied especially for bridge structures, and many projects that monitor the dynamic behavior of large bridges, such as Akashi Kaikyō Bridge (Sumitro et al. 2001), and Tamar Bridge (Cross et al. 2013), have been carried out. SHM of building structures too is gradually gaining popularity. For example, in recent years, some commercial monitoring systems for building structures have been marketed and increasingly applied to high-rise buildings and large-scale structures. However, compared to bridge structures, the application of SHM for building structures is still limited. One possible reason may be the limited monitoring information obtained considering the high cost of such measurement. In such monitoring systems, the floor response acceleration of a building is measured, and the displacement or other indexes are calculated. It is possible to detect some change in the

Jun Iyama

iyama@arch1.t.u-tokyo.ac.jp

1 Department of Architecture, Graduate School of Engineering, The University of Tokyo, 7-3-1 Hongo, Bunkyo-ku, Tokyo 113-8654, Japan natural frequency, the damping factor of the building, or the mode shape of the vibration. However, understanding the kind of structural damage indicated by the change and determining whether the building is damaged still remain a challenge. Arakawa and Yamamoto (2004) performed long-duration monitoring of response floor acceleration of a 120-m-high 23-story steel building with a damping wall and reported that the natural period of the building decreased by 2.7-3.4\% in 60 months; however, the reason for this decrease has not been explained. Iiba et al. (2012) investigated the predominant frequency in response before and after the Great East Japan Earthquake, and reported changes of about $20 \%$ for reinforced concrete (RC) buildings and about $5-10 \%$ change for steel buildings even in buildings where no particular damage was observed in the structure. These studies showed that the predominant frequency may fluctuate even if there is no structural damage. Some researchers presumed that these changes may be caused by the crack extension of $\mathrm{RC}$ walls, slight damage to nonstructural components, or changes in of soil conditions; however, obtaining evidence to support these presumptions is difficult.

Strain may be used as an alternative index that reflects the structural properties and performance better. Strain measurement is widely performed for bridge structures, but it has been rarely applied for actual building structures. With regard 
to the application of strain measurement to architectural steel structures, Kurata et al. (2013), Li et al. (2015) and Li et al. (2017) proposed a method to detect fractures in structural members of a steel structure by measuring the microstrain amplitude with piezo sensors. This method is based on the principle that the vibration amplitude of microstrain, which is caused by ambient ground vibration, near a structural member will decrease when the member is fractured and loses the ability to transfer stress. Matarazzo et al. (2018) extended the method for multiple fractures and validated it through the shaking table test of a steel moment-resisting frame with a damaged link where the fracture is supposed to occur intentionally. They proposed a damage index that represents structural damage and is calculated as the change ratio of the strain amplitudes before and after an earthquake.

If the absolute value of the strain amplitude could be measured, there would be no need to use data measured before the earthquake, and it would be possible to evaluate the remaining performance only from the data measured after the earthquake. The aim of this study was to detect structural damages in a structural element of a structural frame more directly by measuring the strain amplitude in structural steel members caused by microtremor or small aftershocks. This enables direct comparison between measured and analytically calculated values. In this paper, first the background and outline of the damage detection method based on micro strain measurement is presented and then the method is applied to the results of a large-scale shaking table test where more realistic beam-end fractures occurred. An index called local stiffness is defined and calculated from the measured strain data. Through comparison between the measured value and the analysis result of the local stiffness, the applicability of this method is discussed.

\section{Detection Method of Structure Damage}

When a steel structural member in a building moment frame fractures or suffers severe structural damage, the section force (e.g., bending moment and axial force) of this member and its adjacent members may change. When a crack initiation or fracture occurs, the stress transferability of the structural member decreases, and therefore, the stress amplitude is presumed to decrease. Structural damage may be detected by determining this change. In this section, a method to detect this change is presented. The method is similar to the one proposed by Kurata et al. (2013) in principle, but there some differences in terms that this method handles the absolute values of strain and section forces. In the following paragraphs the differences are explained in detail.

Strain measurement provides information on the internal section force at section $i$ at time $t, S_{i}(t)$. Here, $S_{i}(t)$ can be any section force, e.g., bending moment, axial force, or shear force. The index $i$ generally represents the node or section of interest and may be later substituted for a node or section name. The 1st mode amplitude is extracted by the Fourier transform of $S_{i}(t)$, which is denoted by $\hat{S}_{i}\left(\omega_{\text {peak }}\right)$. The hat $(\wedge)$ indicates the Fourier transform, and $\omega_{\text {peak }}$ is the predominant frequency observed in the Fourier amplitude spectrum. $\left|\hat{S}_{i}\left(\omega_{\text {peak }}\right)\right|$ represents the amplitude of the section force at the predominant frequency, and if the structural member near the section $i$ suffers damage such as cracking or fracture, $\left|\hat{S}_{i}\left(\omega_{\text {peak }}\right)\right|$ is considered to decrease. Therefore, it may be possible to detect damage by detecting the decrease in $\left|\widehat{S}_{i}\left(\omega_{\text {peak }}\right)\right|$. However, the magnitude of this value is also affected by the magnitude of the global displacement response of the frame. Therefore, considering one location in the frame, the displacement is used to normalize the section force amplitude. The displacement used for normalization is referred to as "representative displacement" $d_{r}$ Thus, the index of interest is defined as follows.

$K_{i}=\frac{\left|\widehat{S}_{i}\left(\omega_{\text {peak }}\right)\right|}{\left|\widehat{d}_{r}\left(\omega_{\text {peak }}\right)\right|}$

This value is the ratio of section force amplitude to the global displacement amplitude under the 1st-mode vibration, and it is physically interpreted as the stiffness of a structural member near the measurement section. Therefore, in this paper, $K_{i}$ is referred to as "local stiffness." As discussed earlier, if the stiffness of a member decreases because of structural damage such as crack extension or fracture, this value is expected to change (decrease, in many cases). It should be noted that local stiffness is calculated using the Fourier amplitudes of the measured data; therefore, it is not affected by the long-term drift or DC component. Consequently, it is not necessary to measure data continuously over a long period of time.

The local stiffness is calculated from the measured section force and the displacement under microtremors or small aftershocks. The section force can be measured, for example, by strain gauges. A displacement cannot be easily measured directly, but the Fourier amplitude of the displacement can be converted from that of the acceleration, which can be easily measured using an accelerometer using the following equation:

$\widehat{d}_{r}\left(\omega_{\text {peak }}\right)=\frac{\left|\widehat{a}_{r}\left(\omega_{\text {peak }}\right)\right|}{\omega_{\text {peak }}^{2}}$

where $a_{r}$ is the acceleration measured at a representative location.

The local stiffness can also be estimated easily through a static pushover analysis of the frame. The value 
estimated from the static analysis is denoted as $K_{i}^{*}$ in this paper. When the building structure is intact, the measured $K_{i}$ should be the same as the estimated $K_{i}^{*}$, and when member $i$ (or the adjacent members) incurs any structural damage, $K_{i}$ is expected to be much smaller than $K_{i}^{*}$.

The local stiffness $K i$ can be measured for any cross-section, but from a damage-detection viewpoint, $K i$ must be measured where stress and strain are maximally changed owing to the damage. For example, the $K i$ of a beam-end fracture must be measured at the beam end, where the largest change in the bending moment is expected. However, as the stress distribution is nonuniform at a beam end, bending moment is difficult to measure therein. For this reason, $K i$ at a beam end is usually calculated by extrapolating the strains measured by at least two strain gauges attached to the two cross sections in the center portion of the beam, as demonstrated in the shaking-table test presented in Sect. 3 and in other structural tests.

One of the advantages of the local stiffness defined above is that the measurement position can be determined using prior analysis. Monitoring the entire building would require impractically large number of sensors, and in practical applications of this method, it is important to select the correct measurement locations according to the damage to be detected. Using the local stiffness shown above, the values before and after damage can be obtained using prior analysis; therefore, it is possible to identify the measurement locations where the damage can be most easily detected.

In addition, there are many factors those change the stress of a member in the structure of an actual building; even if the measured local stiffness changes, it is difficult to reliably assess whether the change is owing to the intended damage. However, according to this method, it is possible to estimate in advance the type and degree of change in local stiffness that will occur, which can be used as important information to determine the cause. For example, if a local stiffness change is detected, but the degree of the change is smaller than that estimated in advance, it could be determined that some phenomena occurred, although the possibility of the target damage might be low. If the reliable detection of specific damage were required, this could be achieved by measuring the target member and surrounding members. Upon the fracture of the target, a significant change in the target member would be observed; however, other members would reveal a smaller change or no change with respect to the prior analysis.

Since the strain gives only information in a very narrow range, the information obtained by measuring a small number of places is limited, but it is an advantage of this method that the measurement location and the threshold of judgment can be determined by prior analysis according to the purpose of damage detection.

\section{Application of the Proposed Method}

\subsection{Target Shaking Table Test}

The following sections verify the proposed method in shaking table tests of steel frames performed in a past research project. The shaking table test is detailed in Kubota et al. (2017) and Kubota et al. (2018). Its main purpose is clarifying the process by which the high-rise steel frame eventually collapses under a huge earthquake input. The recorded data have not been thoroughly analyzed from a damage-detection viewpoint. In this paper, the bending moments before and after the beam-end fracture were determined from the recorded test data, and compared. The data were provided by the ASEBI system operated by the National Research Institute for Earth Science and Disaster Resilience (NIED).

The target specimen is a $1 / 3$-scale 18 -story 3 -bay steel frame structure subjected to the shaking table test. The dimensions of the specimen and the measurement locations are shown in Fig. 1. Figure 2 shows the frame plan and elevation of the specimen. In the excitation test, unidirectional excitation in the y-direction was applied. The location of strain gages mounted on the beams and columns are shown by triangles. For the representative displacement, the record of the wire displacement sensor located at the 12th floor level, which is the sensor installed at the highest location in this test, was used in this study.

The beam is built up $\mathrm{H}-270 \times 85 \times 6 \times 12$ (SS400). The connection and the slab beam are shown in Fig. 2. As shown in the figure, the distance between the centroids of the steel section and the slab above the deck plate is $171.5 \mathrm{~mm}$.

The frame in $\mathrm{X} 2$ axis is the focus of this study. The naming rules of beam elements and locations used in the later sections of this paper are explained in Fig. 3. The beam and column names are already shown in Fig. 1. Each beam or column has two sections (sections I and J) where strain gages are installed. The connecting nodes of a beam or column are denoted as nodes 0 and 1 . The floor number, story number, node number, and/or section number may be omitted if not necessary. The locations of the installed strain gages are shown in Fig. 4. The I and J sections of each beam and column were outfitted with four strain gages and two strain gages, respectively. As the concrete slab sits on the upper flange of the beam, strain gage $\varepsilon 1$ was attached to the back surface of the upper flange of the beam.

The input waveform of the excitation was designed to emulate a three-linked earthquake with hypocenters in the Tokai Trough, Tonankai Trough, and Nankai Trough. First, 2100 seismic wave simulations were performed by 


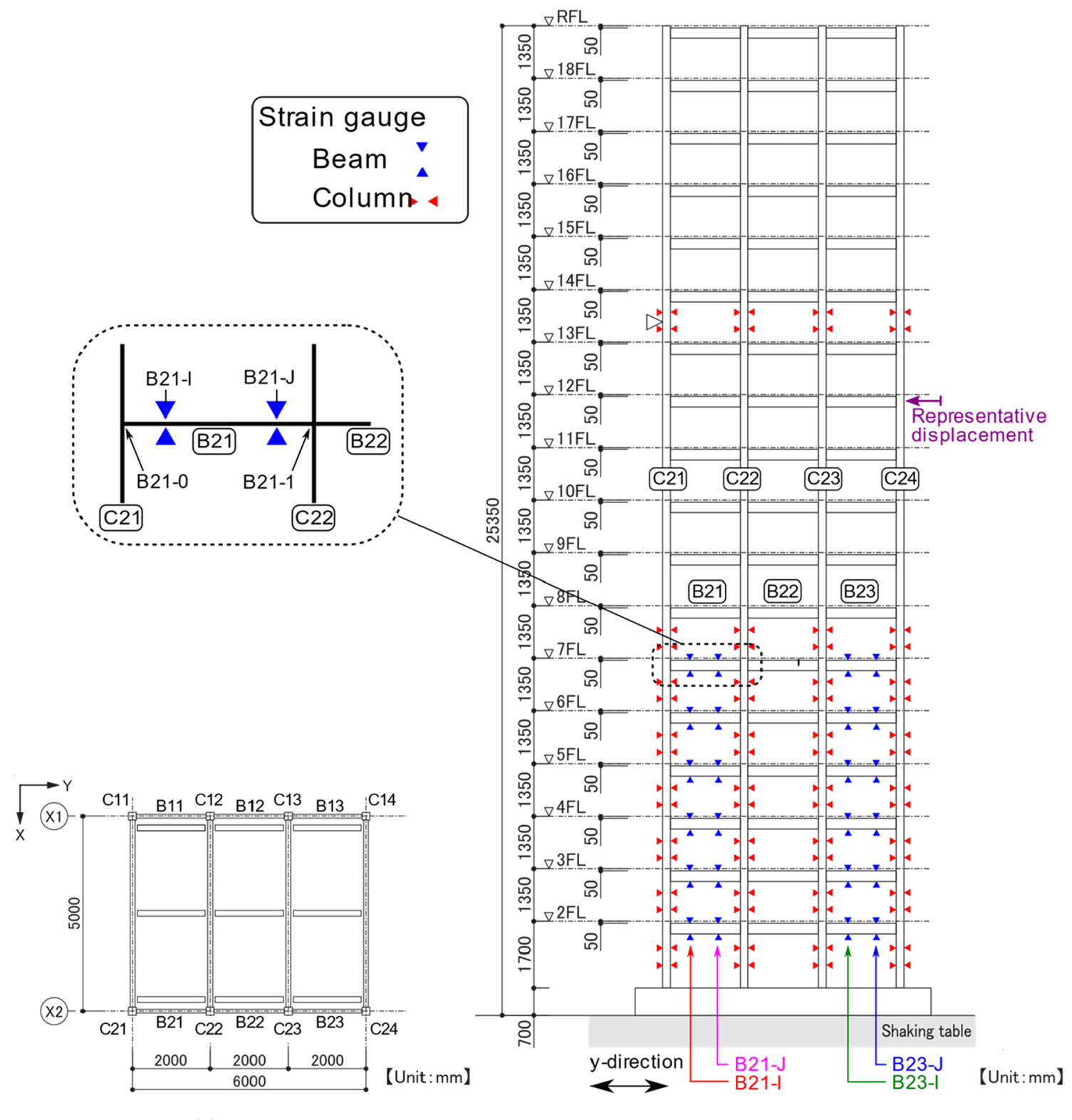

(a) Frame plan

(b) Frame elevation

Fig. 1 Specimen shape and measurement locations (Created from Figs. 2 and 3 in Kubota et al. (2018))

the method proposed in Sato et al. (2010), obtaining 2100 possible response spectra (black dashed lines in Fig. 5). The average level determined from the simulation results was set to a spectral pseudo velocity (denoted by $\mathrm{pSv}$ ) of $110 \mathrm{~cm} / \mathrm{s}$, and the bilinear spectrum (solid gray line in Fig. 5) was determined as the target spectrum. As the input ground-motion waveform, we simulated a seismic waveform that matched the target spectrum. Figure 6 shows the created seismic acceleration waveforms. The gray dotted line in Fig. 5 is the velocity response spectrum calculated by the author from the acceleration record on the shaking table. The response spectrum of the applied waveform well agreed with the target spectrum. During the excitation, the time axis of the input waveform was shortened by $1 / \sqrt{3}$ because the test specimen was a $1 / 3$ scale model. To change the earthquake intensity, the acceleration of this waveform was multiplied by magnification factors, then input to the shaking table.

Before and after the seismic wave tests, the vibration characteristics of the specimen were explored in randomwave excitation tests. The waveforms and the velocity response spectrum are shown in Fig. 7a and b, respectively. The small intensity ensured that the test specimen remained in the elastic range. The response to this random-wave test 


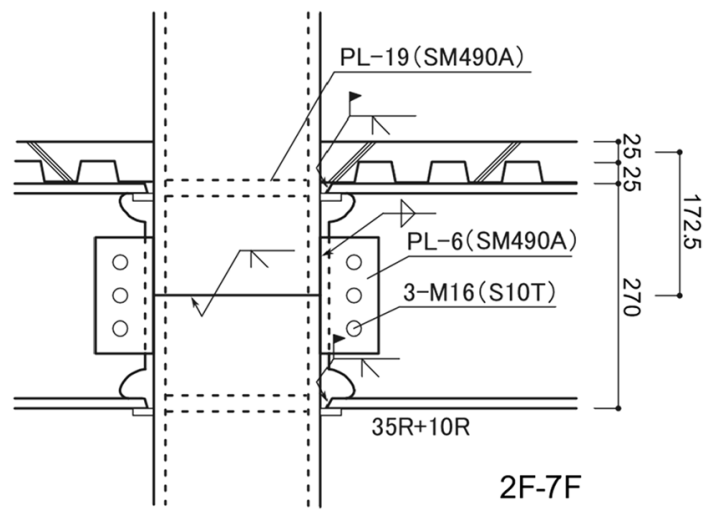

Fig. 2 Connection details

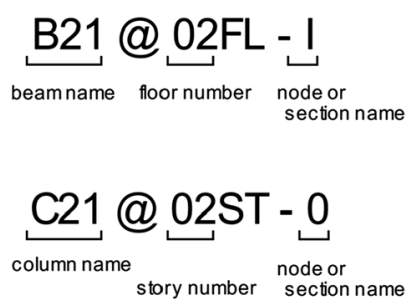

Fig. 3 Symbols representing node and section locations

was input to the proposed damage-detection method (as explained in the following subsections).

\subsection{Shaking Test Sequence and Observed Damage}

The sequence of shaking table tests and the damage observed in the beams on the 2nd and 5th floor are summarized in Fig. 8 (created from Kubota et al. 2018). The specimen was subjected to 12 excitation tests using strong ground motions. These strong motion tests are assigned names starting with "pSv," followed by a number representing the intensity of the motion, as shown in the lower part of Fig. 8. The beam end first fractured during the pSv220 test. As the motions intensified, the number of fractures in the beam ends increased.

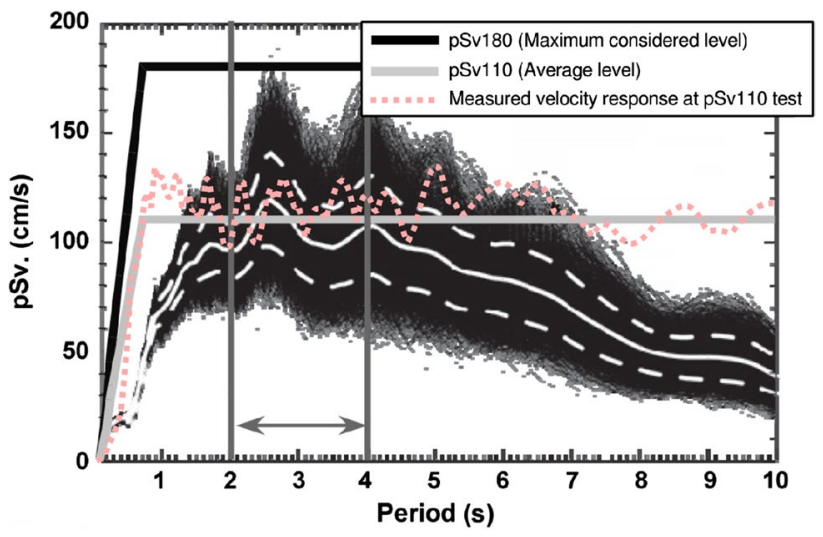

Fig. 5 Target spectrum of the simulated seismic waveform (Created from Fig. 13 in Kubota et al. 2018)

During the pSv420-3 test, the specimen was significantly deformed and leaned against the protection frame, so this test was terminated. Figures 9 and 10 show the whole frame and the observed beam-end fracture after the pSv420-3 test, respectively.

Before and after each strong motion test, a random excitation test using a smaller random wave was performed in order to investigate the vibration characteristics of the test frame. In this paper, these random excitation tests are termed "R1" to "R14" as shown in Fig. 8. Figure 11 shows a representative time history of the recorded strain and its Fourier spectrum. The solid(red) and dashed(blue) lines in the figure represent the strains measured by the $\varepsilon_{1}$ and $\varepsilon_{4}$ gages, respectively, in the B21@FL02-I section during the R6 test after the pSv110-1 test. As evidenced in Fig. 11a and b, the phases of the solid(red) and dashed(blue) lines were almost opposite, indicating that a bending moment was applied. Furthermore, the slightly different amplitudes of the two lines imply the presence of an axial force. The time histories and spectra of the two gages almost match, and the bending moment and axial force calculated from these data are considered to be sufficiently accurate. Based on these strain time histories measured under random excitation tests, the changing $K_{i}$ values representing structural damages of the member will be analyzed in the following discussion.

Fig. 4 Locations of strain gages

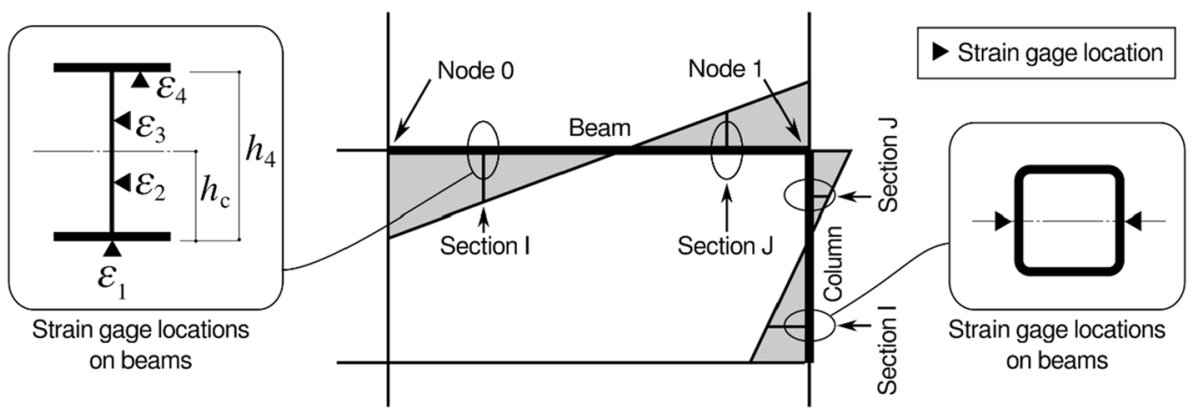


Fig. 6 Simulated seismic waveform (Fig. 14 in Kubota et al. 2018)
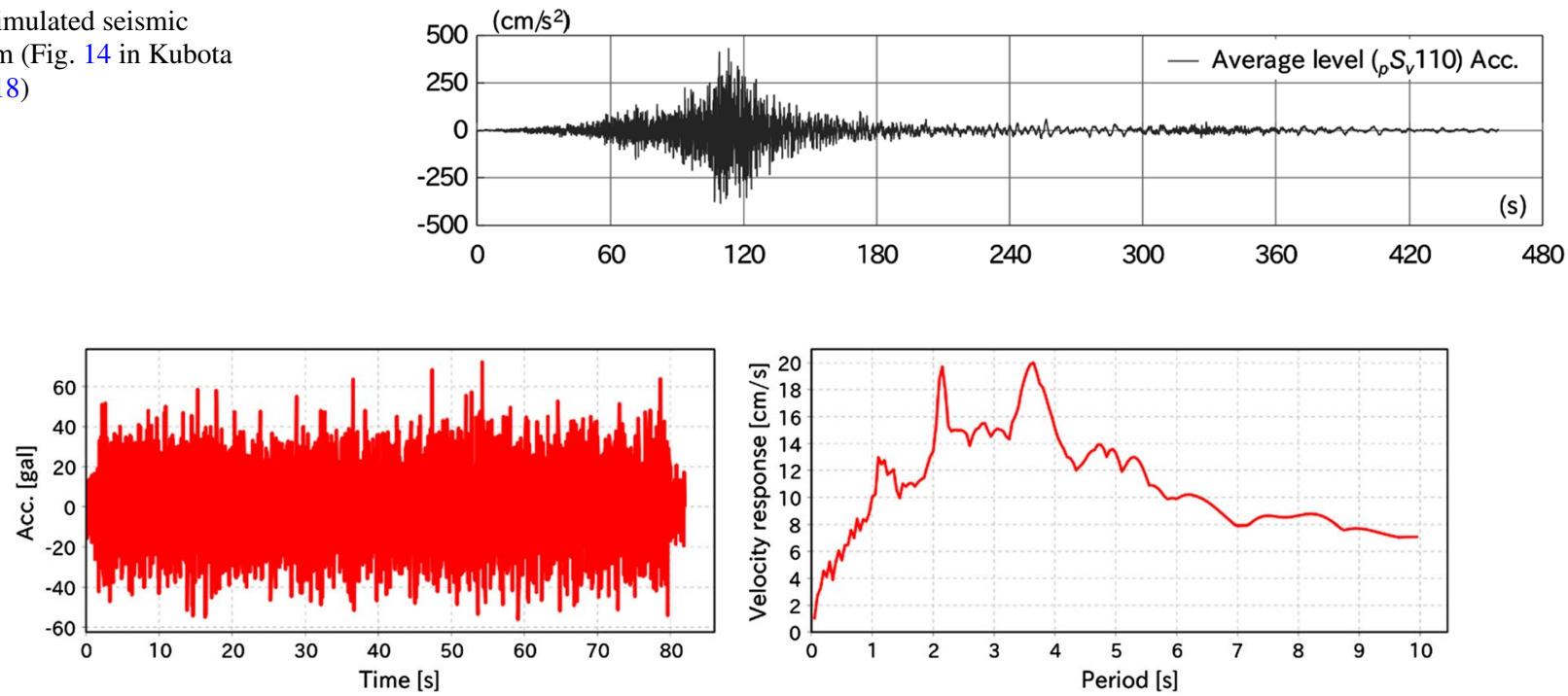

Fig. 7 Waveform and spectrum used for the random wave test

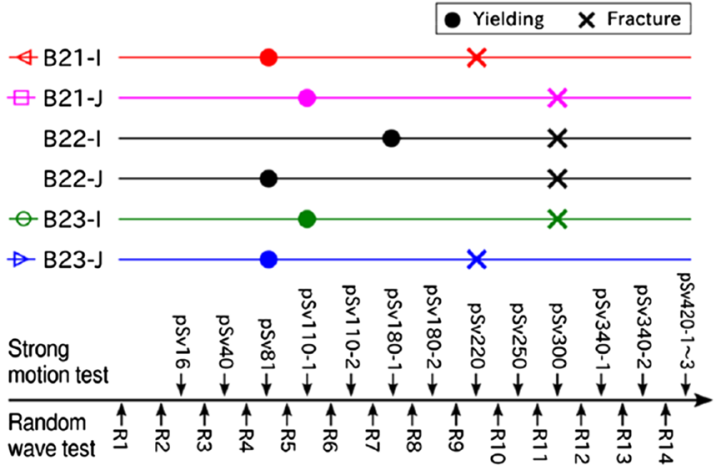

(a) $2 \mathrm{FL}$

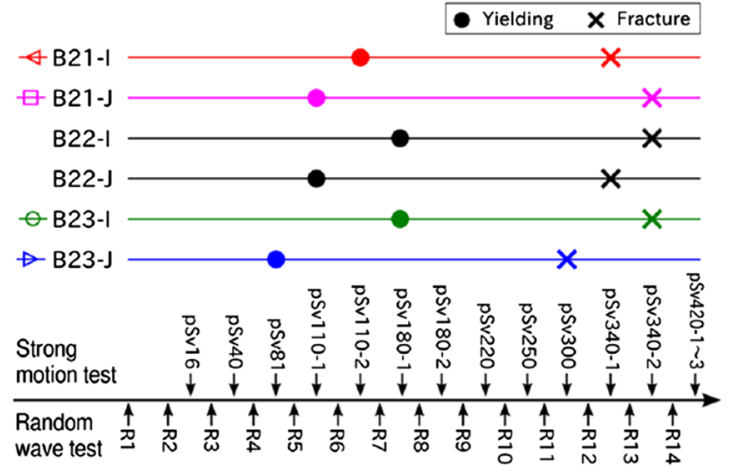

(b) $5 \mathrm{FL}$

Fig. 8 Shaking test sequence and observed damage

Figure 12 shows changes in the predominant period calculated from the random wave tests. It is seen that the 1stmode predominant period hardly changed up to R10 test, where two beam ends on the 2nd floor had already fractured. In R12 test, the predominant period exhibited a $25 \%$ increase compared to R10 test, where all the beam ends up to the fourth floor fractured (Kubota et al. 2018). The predominant period changes because of fracture of the structural elements; however, when only few elements are fractured, the change in the predominant period is too small to detect only from the change in the predominant period of floor acceleration records.

\subsection{Frame Structural Analysis}

A frame structural analysis was performed using ABAQUS software to calculate the estimated local stiffness $K_{i}^{*}$. A frame model was created with beam elements where the column base was fixed and no RC floor slab was modeled. First, using this model, a modal analysis was performed to obtain the natural periods and mode shapes. The obtained natural period is $1.26 \mathrm{~s}$, which is larger than the period of $1.15 \mathrm{~s}$ observed in the test.

Then, a static pushover analysis was performed by applying the 1st mode deformation shape. From the analysis, the representative displacement, $d_{\mathrm{r}}$-the one measured at 12th floor level, and the bending moment in all the beams and columns are obtained. The result of the analysis will be shown in a later section with the measured results. 


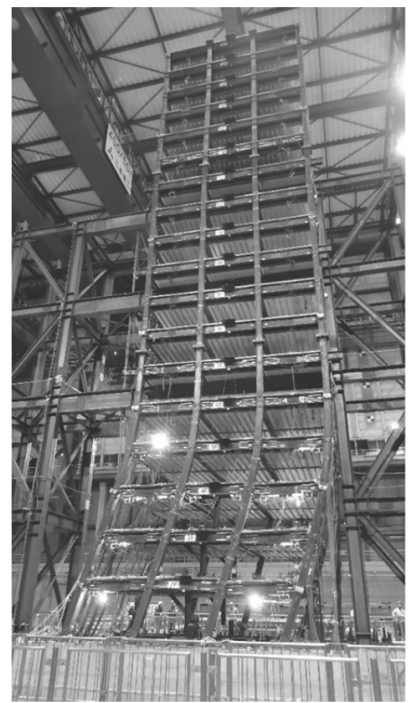

Fig. 9 Specimen after the last test (pSv420-3) (Photograph 3 in Kubota et al. 2018)

\subsection{Calculation of Local Stiffness from Measured Strain}

Here, the calculation of the local stiffness from measured strain time history is explained. The local stiffness at each connection node was calculated and then compared to the value estimated from the static pushover analysis.

A beam was considered as an example. Each measurement section, I and J, has four strain gages, and the measured values are denoted as $\varepsilon_{1}-\varepsilon_{4}$ (see Fig. 4). The following calculation uses only $\varepsilon_{1}$ and $\varepsilon_{4}$. From the strain measured by the strain gages, the bending moment $M_{i}$ and the axial force $N_{i}$ at section $i$ were calculated as follows.

$M_{i}=E I \frac{\left(\varepsilon_{1}-\varepsilon_{4}\right)}{h_{4}}$

$N_{i}=E A \frac{\left(h_{4}-h_{c}\right) \varepsilon_{1}+h_{c} \varepsilon_{4}}{h_{4}}$

where $A$ and $I$ are the section area and inertia moment, respectively, of the target section $i$ (i.e., I or $\mathrm{J}$ in this example). $h_{c}$ and $h_{4}$ are the distances from the bottom of the section to the center of the section and to the $\varepsilon_{4}$ gage, respectively. Note that $M_{i}$ calculated by Eq. (2) is the bending moment of the steel beam only and does not account for the bending moment transferred by the slab. The bending moment of the composite beam, including the effect of the slab, is calculated as follows:

$M_{\text {composite }, i}=M_{i}+e N_{i}$

where $e$ is the distance between the centroids of the steel beam section and the slab section $(171.5 \mathrm{~mm}$ for this specimen).

From $M_{\text {composite, I }}$ and $M_{\text {composite,J }}$, it is possible to calculate the bending moment at nodes 0 and 1 by extrapolation. They are denoted as $M_{\mathrm{b}, 0}$ and $M_{\mathrm{b}, 1}$, respectively, and the subscript $\mathrm{b}$ indicates that the value is calculated from beam strain. From these values, the local stiffness at the nodes can be calculated by substituting $M_{\mathrm{b}, 0}$ or $M_{\mathrm{b}, 1}$ or $S_{i}$ in Eq. (2) as follows.
Fig. 10 Observed damage after the test (Photograph 4 in Kubota et al. 2018)

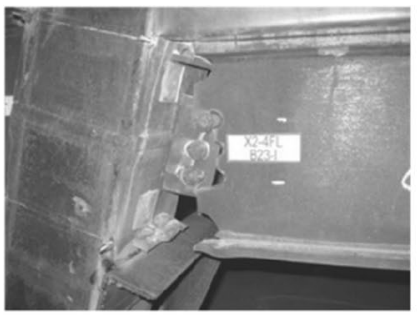

(a) Beam end

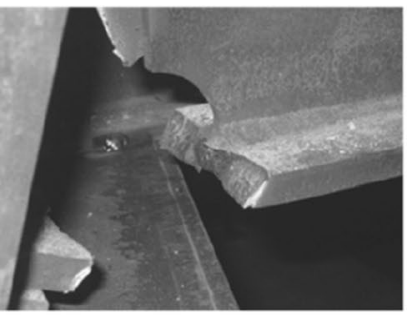

(b) Lower flange

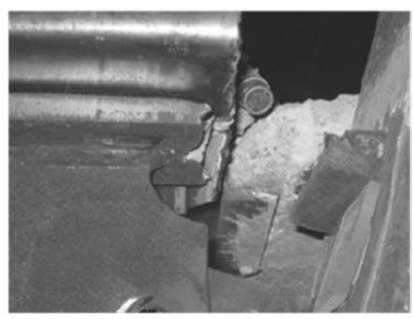

(c) Upper flange

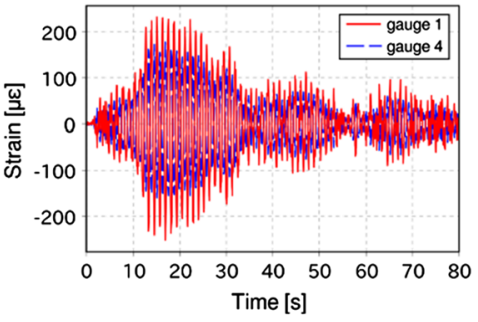

(a) Time history

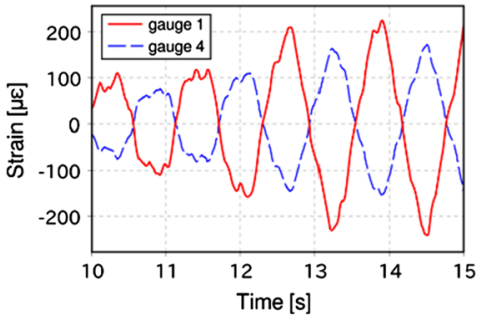

(b) Time history (close up)

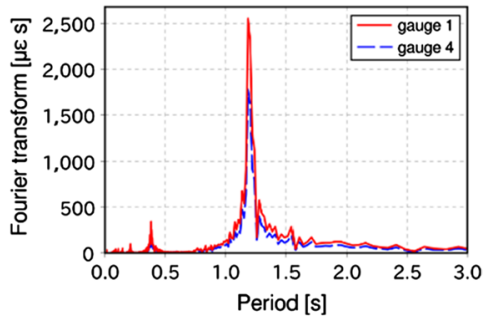

(c) Fourier spectrum

Fig. 11 Recorded time history and Fourier spectrum of the strain response during a random wave test (R6) 


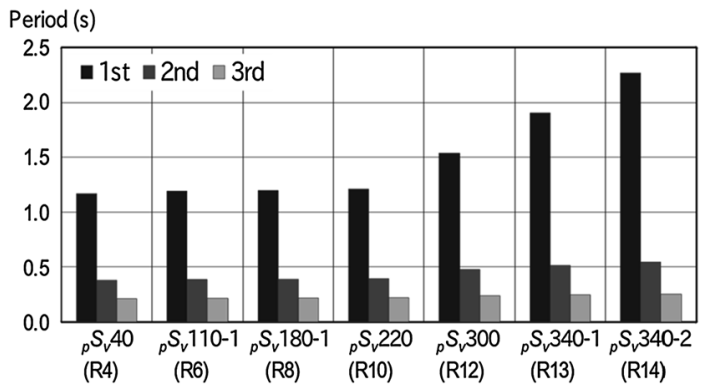

Fig. 12 History of predominant periods (Created from Fig. 18 in Kubota et al. 2018)

$K_{\mathrm{b}, i}=\frac{\left|\tilde{M}_{\mathrm{b}, i}\left(\omega_{\text {peak }}\right)\right|}{\left|\tilde{d}_{\mathrm{r}}\left(\omega_{\text {peak }}\right)\right|}$

where $i$ is the node number ( 0 or 1 in this example), and $d_{\mathrm{r}}$ is the representative displacement.

Similarly, the local stiffness of the node can also be calculated from the column strain. These stiffness values are denoted as $K_{\mathrm{c}, i}$ in this paper. In the calculation, the eccentricity can be assumed as 0 since the axial force does not create the bending moment. Theoretically, the sum of the $K_{\mathrm{b}, i}$ 's of the beams and the sum of $K_{\mathrm{c}, i}$ 's of the columns connected to a single node should be the identical.

\subsection{Calculated Values of Local Stiffness and Relation to Beam-end Fracture}

From the strain time history during each random wave test (R1-R14) measured by the strain gages pasted on the B21 and B23 beams, the local stiffness at the nodes connected to the beams are calculated by using the equations explained in the previous section. In this section, the local stiffness at these nodes are denoted as $K_{\mathrm{B} 21-0}, K_{\mathrm{B} 21-1}, K_{\mathrm{B} 23-0}, K_{\mathrm{B} 23-1}$ where the subscripts represent the node name. Figure 13 shows the changes in the values for the 2nd and 5th floors.
In the figure, the estimated values, $K_{i}^{*}$, are also shown with horizontal straight lines. It should be noted that there are only two lines, $K_{\mathrm{B} 21-0}^{*}$ and $K_{\mathrm{B} 21-1}^{*}$ in each figure, but they are identical to $K_{\mathrm{B} 23-1}^{*}$ and $K_{\mathrm{B} 23-0}^{*}$, respectively, because the frame is horizontally symmetric.

The measured $K_{i}^{\prime}$ 's are stable up to R9. The measured values are slightly larger than the estimated values shown by the horizontal lines, indicating that the actual stiffness of the system is larger than the estimate. These differences may be a result of the difference between the finite element model and actual specimen structure. Although the exact reason is unknown, this difference is consistent with the fact that the calculated natural period is slightly longer than the actual measured period, as mentioned in Sect. 3.3.

Kubota et al. $(2017,2018)$ reported that some cracks in steel beam flanges were observed after pSv180-2 test. However, there is no clear change in $K_{i}$ value up to R9 test, as shown in Fig. 13. It may be difficult to detect crack initiation or extension by this method.

As shown in Fig. 13a, after beam-end fracture occurred at B21 and B23 beam ends in the 2nd floor during pSv220 test between R9 and R10, $K_{\mathrm{B} 21-0}$ and $K_{\mathrm{B} 23-1}$ showed a drastic decrease, and the values became much smaller than the

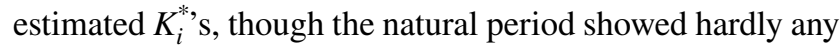
change as shown in Fig. 12. Similarly, large decreases were observed in other locations (Figs. 5b, 12a). A comparison of Figs. 8 and 12 shows that all of these locations coincide with the beam-end fracture. Therefore, it may be possible to detect fractures by comparing $K_{i}$, which is measured only after an earthquake, with the estimated $K_{i}^{*}$ even if the global dynamic behavior of the frame hardly changed.

Further, Fig. 13b shows a sudden increase at B21-1 and B23-0 between R12 and R13. This increase may be attributed to the fracture at B22-1, causing a redistribution of the stress and consequently increasing the internal forces at B21 and B23. This presumption can explain the fact that the degree of increase at B23-0 directly related to the fractured B22-1 is much larger than that at B21-1. It may be possible

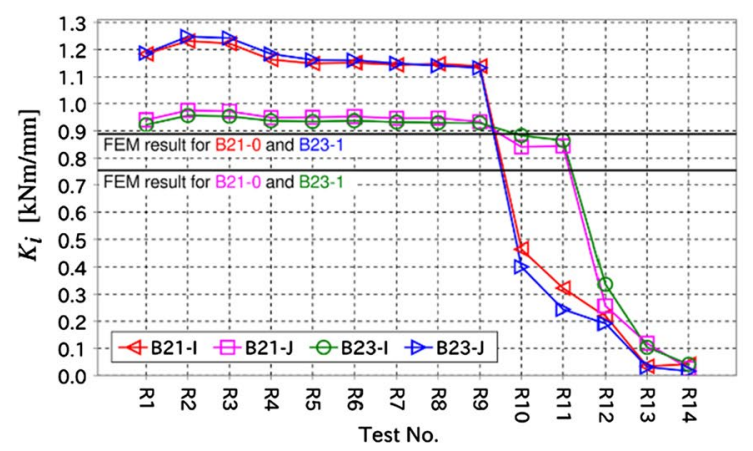

(a) $2 \mathrm{FL}$

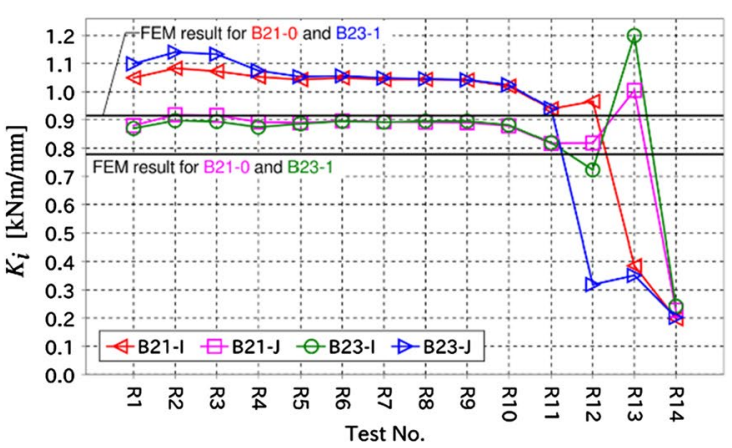

(b) $5 \mathrm{FL}$

Fig. 13 History of local bending stiffness of beams on the second floor (left) and the fifth floor (right) 
to employ such increase of the local stiffness to detect fractures at any other locations where the strain is not measured by any method to decompose the value as proposed by Matarazzo et al. (2018).

In addition, other small changes are observed in intact locations. For example, in Fig. 13a, some increasing trend is observed during R9 and R11 in B21-2 and B23-1 edges where no fracture was observed at that time. These changes may be also attributed to stress redistribution and may be an implication of a fracture at any other location. Further study is necessary to utilize these small and gradual changes for fracture detection.

Figure 14 shows graphs similar to Fig. 13. The $K_{\mathrm{c}}$ values calculated from the measured strain of the columns connected to the 2nd- and 5th-floor beams are shown in Fig. 14. The vertical axis represents the sum of $K_{\mathrm{C}, i}$ values at the nodes of each column, as calculated from the strain measured in the columns at the upper and lower stories of the 2nd or 5th floor. It is seen that $K_{\mathrm{C} 21}$ and $K_{\mathrm{C} 24}$ values shown in Fig. 14 are almost identical to $K_{\mathrm{B} 21-0}$ and $K_{\mathrm{B} 23-1}$ shown in Fig. 13, respectively, as expected theoretically from the equilibrium of the bending moment at the node. The measured strain is very small, but the calculated local stiffness from such small strain are sufficiently stable and reliable and are comparable to the absolute values. The trend of the change in $K_{\mathrm{c}}$ values shown in this figure are similar to that of $K_{\mathrm{b}}$ values shown in Fig. 13, and it is shown that all the sudden decreases coincide with the fracture of the beam end connected to the column.

Thus, we can conclude that the $K_{\mathrm{b}}$ values and $K_{\mathrm{c}}$ values are almost identical and both can be used for fracture detection for the steel frame specimen in the present study. However, note that the specimen did not have any walls and other nonstructural components. Actual buildings have many nonstructural elements attached to the structural frame, and these elements may transfer some magnitude of the internal force and may disturb the balance of the $K_{\mathrm{b}}$ and $K_{\mathrm{c}}$ values. The effect of such nonstructural components on $K_{i}$ values and the applicability of this method for actual building structures should be studied in greater details in the near future using data measured in more realistic specimens and actual buildings.

\section{Conclusions}

When a structural damage such as a crack initiation or fracture occurs, the stress transferability of the structural member decreases, and therefore, the stress amplitude is presumed to decrease. Structural damage may be detected by determining this change. To capture this change, an index named local stiffness or $K_{i}$ was defined and calculated in this study. This value has a physical meaning as a stiffness, and it is easily estimated by simple structural analysis. As long as the structural members are intact, the measured $K_{i}$ value should be identical to the analysis result. As structural damage (e.g., crack extension, fracture, etc.) proceeds, the $K_{i}$ value is expected to deviate, and in many cases, to decrease compared to the analysis result. Therefore, it may be possible to detect structural damage by observing the change of the $\mathrm{Ki}$ value from the analysis result.

This method was applied to a large-scale shaking table test result. The target specimen was an 18-story steel moment-frame. The specimen was subjected to 12 strong earthquake ground motions as well as random small wave excitation tests before and after every ground motion excitation. Beam fracture and column base local buckling occurred, and finally, the specimen lost the restoring force and collapsed. From the strain and displacement data measured during small amplitude random excitations before and after strong earthquake excitations, the $K_{i}$ value was calculated and compared to the analysis value to investigate whether this value can be used to detect structural damage. The comparison showed that it is considered possible to detect fracture by finding sudden and significant changes in the $K_{i}$ value. In many cases, the value becomes much

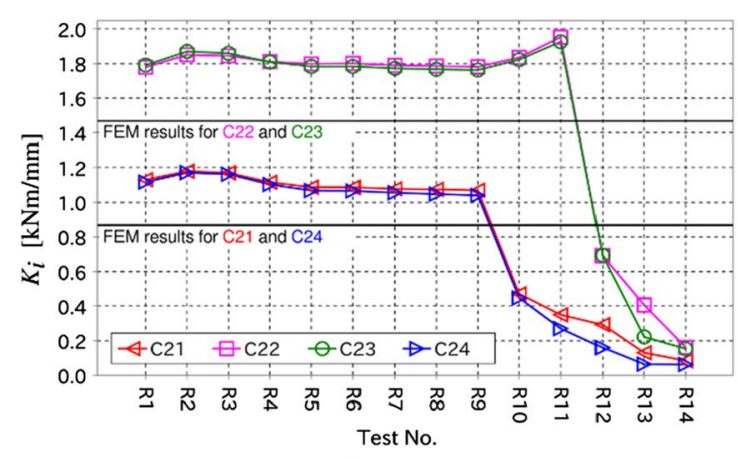

(a) $2 \mathrm{FL}$

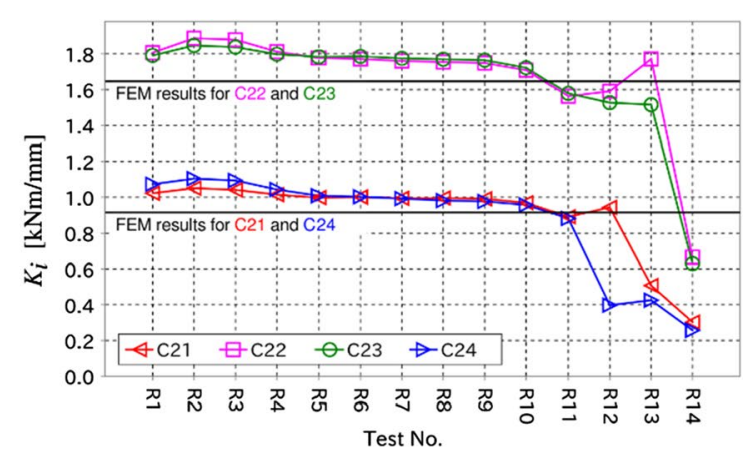

(b) $5 \mathrm{FL}$

Fig. 14 History of local bending stiffness of columns on the second floor (left) and the fifth floor (right) 
smaller than the analysis result; therefore, it may be easy to detect this change. It is possible to use even column strain data to detect beam-end fractures because such fractures also have a great effect on the column bending moment as well as the beam bending moment. However, it may be difficult to detect crack initiation or extension because small cracks do not greatly change the member stiffness and therefore the $K_{i}$ value.

This paper tested the feasibility of detecting fractures from local stiffness values using the recorded data in a shaking table test of a large steel frame specimen subjected to beam-end fractures. Because it detects the changing internal forces (axial forces, shear forces, and/or bending moments), the method can potentially detect any structural damage in any structural system, provided that two conditions are met: 1) the damage affects the distribution of the internal force distribution, and 2) the change can be measured by strain gages or other equipment. These conditions could be satisfied by selecting an appropriate location for damage detection and by using high-precision strain gages. However, whether this method can capture the fractures in real earthquake-damaged buildings is difficult to discern, because structural damage situations in actual buildings are difficult to measure. Instead, one must continue verifications by measuring a large number of real buildings and shaking table tests with more realistic specimens.

Acknowledgements The shaking table test, the data of which was used in this paper, was conducted at E-Defense in 2013 under a title of "Quantification of collapse margin of steel high-rise structure" as part of a research project titled "Maintenance and Recovery of Functionality in Urban Infrastructure" sponsored by Ministry of Education, Culture, Sports, Science and Technology of Japan. The data were provided through ASEBI system (https://www.edgrid.jp/) of National Research Institute for Earth Science and Disaster Resilience (NIED).

Open Access This article is licensed under a Creative Commons Attribution 4.0 International License, which permits use, sharing, adaptation, distribution and reproduction in any medium or format, as long as you give appropriate credit to the original author(s) and the source, provide a link to the Creative Commons licence, and indicate if changes were made. The images or other third party material in this article are included in the article's Creative Commons licence, unless indicated otherwise in a credit line to the material. If material is not included in the article's Creative Commons licence and your intended use is not permitted by statutory regulation or exceeds the permitted use, you will need to obtain permission directly from the copyright holder. To view a copy of this licence, visit http://creativecommons.org/licenses/by/4.0/.

\section{References}

Arakawa, T., Yamamoto, K. (2004). Frequencies and damping ratios of a high rise building based on microtremor measurement. In: 13 th world conference on earthquake engineering, Vancouver, BC, Canada, August 1-6, 2004, paper no. 48.

Cross, E. J., Koo, K. Y., Brownjohn, J. M. W., \& Worden, K. (2013). Long-term monitoring and data analysis of Tamar Bridge. Mechanical Systems and Signal Processing, 35(1-2), 16-34.

Kubota, J., Suzuki, Y., Suita, K., Sawamoto, Y., Kiyokawa, T., \& Koshika, N., et al. (2017). Experimental study on the collapse process of an 18-story high-rise steel building based on the largescale shaking table test. In 16th world conference on earthquake engineering (16WCEE), paper no. 792.

Kubota, J., Takahashi, M., Suzuki, Y., Sawamoto, Y., Koetaka, Y., Iyama, J., et al. (2018). Collapse behavior of 18story steel moment frame on shaking table test under long period ground motion. Journal of Structural and Construction Engineering, 83(746), 625-635. https://doi.org/10.3130/aijs.83.625.

Kurata, M., Li, X., Fujita, K., \& Yamaguchi, M. (2013). Piezoelectric dynamic strain monitoring for detecting local seismic damage in steel buildings. Smart Materials and Structures, 22, 115002.

Li, X., Kurata, M., \& Nakashima, M. (2015). Evaluating damage extent of fractured beams in steel moment-resisting frames using dynamic strain responses. Earthquake Engineering and Structural Dynamics, 44(4), 563-581.

Li, X., Kurata, M., \& Suzuki, A. (2017). Decoupling algorithm for evaluating multiple beam damages in steel moment-resisting frames. Earthquake Engineering and Structural Dynamics, 46(7), 1045-1064.

Iiba, M., Okawa, I., Saito, T., Morita, K., \& Hasegawa, T. (2012). Study on the behavior of buildings based on the strong motion records observed at the 2011 off the pacific coast of Tohoku earthquake. Building Research Data No. 138. Japan: Building Research Institute. (in Japanese).

Matarazzo, T. J., Kurata, M., Nishino, H., \& Suzuki, A. (2018). Postearthquake strength assessment of steel moment-resisting frame with multiple beam-column fractures using local monitoring data. Journal of Structural Engineering, 144(2), 04017217.

Sato, T., Okawa, I., Nishikawa, T., Sato, T., \& Seki, M. (2010). Prediction of waveforms of long-period ground motions for hypothetical earthquakes using empirical regression relations of response spectra and phase spectra. Journal of Structural and Construction Engineering (Transactions of AIJ), 75(649), 521-530. (in Japanese).

Sumitro, S., Matsui, Y., Kono, M., Okamoto, T., \& Fujii, K. (2001). Long span bridge health monitoring system in Japan. Proceedings of SPIE, 4337, 517-524.

Publisher's Note Springer Nature remains neutral with regard to jurisdictional claims in published maps and institutional affiliations. 